\title{
Interaction between Neuroendocrinology and Immunology: Hypothalamic-Pituitary-Thyroid Axis in Immunoendocrinology
}

\author{
Landys Z. Guo \\ Department of Biology, College of Arts \& Sciences, University of Kentucky, Lexington, USA \\ Email: lzgu222@g.uky.edu
}

How to cite this paper: Guo, L.Z. (2021) Interaction between Neuroendocrinology and Immunology: Hypothalamic-Pituitary-Thyroid Axis in Immunoendocrinology. Open Journal of Endocrine and Metabolic Diseases, 11, 63-69.

https://doi.org/10.4236/ojemd.2021.112005

Received: December 21, 2020

Accepted: February 5, 2021

Published: February 8, 2021

Copyright $\odot 2021$ by author(s) and Scientific Research Publishing Inc. This work is licensed under the Creative Commons Attribution-NonCommercial International License (CC BY-NC 4.0).

http://creativecommons.org/licenses/by-nc/4.0/

\begin{abstract}
The study of interactions between neuroendocrinology and immunology, or immunoendocrinology, is a recent field with the majority of its development in the last 30 years that involves communication between the nervous, endocrine, and immune systems. Homeostasis, development, aging, metabolism, infection, and inflammation are all influenced by the cross talk between these systems via hormones, cytokines, and neurotransmitters. The nervous system affects the immune system through either the hypothalamus-pituitary axes (adrenal, gonadal, thyroid, growth-hormone) neuropeptide and hormone signals or autonomic nervous system signals of norepinephrine and acetylcholine. On the other hand, the immune system passes feedback through cytokine type and concentration in the blood. Imbalance of any of these systems leads to increased risk in severity of metabolic, psychiatric, inflammatory or autoimmune diseases. These two systems are complex standalone and even more so in their interaction. Thus, the relationship between the immune system and the hypothalamus-pituitary-thyroid axis is necessary to be reviewed.
\end{abstract}

\section{Keywords}

Hypothalamic, Pituitary, Thyroid, Neuroendocrinology, Immunoendocrinology

\section{Introduction}

While immunology and neuroendocrinology had their early beginnings in the 1500 's and 1600's, their fields have been relatively separated in their discoveries. However, in 1952, Dr. Andor Szentivanyi and Dr. Geza Filipp observed that hypothalamic lesions prevented anaphylactic shock in previously immunized ani- 
mals [1]. After discovery and elucidation of the mechanisms of the interferon alpha in 1957 and 1965 respectively, this birthed a foundation to investigate molecular interactions between these two systems [2] [3]. The hypothalamic-pituitarythyroid (HPT) axis was the first neuroendocrine axis to be identified when Caleb Hillier Parry documented his observation of hyperthyroidism in 1786 within his article "Elements of Pathology and Therapeutics" in 1815 [4]. Later on, he also wrote a case report about the relationship between stressful life events and the onset of Grave's disease [4] [5]. Thus, Caleb Hillier Parry is credited with one of the earliest descriptions of the form of hyperthyroidism usually termed Graves' disease.

However, the mechanism of the HPT axis was could not be fully discerned until oxidative phosphorylation in the mitochondria was clarified by Peter Mitchell in 1961 [6]. In the following year, Dr. Tata et al. published a report on the control of basal metabolic rate via thyroid hormones in rodents [7]. Even now, we still continue to have new insights into the actions of thyroid secreting hormone (TSH), triiodothyronine (T3) and thyroxine (T4) in relation with different systems, such as the effects of stress, environment, or epigenetic modifications on growth and development [8].

In immunology, germ theory was solidified with Heinrick Hermann Robert Koch's discovery that bovine anthrax is caused by Bacillus anthracis in 1876 [9]. From there, Robert Koch published the famous Koch's Postulates in 1890, which outlines the four criteria needed to determine if a microbe causes a disease, i.e., the microbe is present in every case of the disease but should not be found in healthy organisms, must be isolatable from the host with the disease and grown in a pure culture, can infect other healthy hosts from the pure culture which should cause the disease, and is recoverable from the experimentally infected host. His postulates were further refined after he encountered asymptomatic carriers of cholera and tuberculosis, and discarded the second phrase of the first postulate. The first virus, the tobacco mosaic virus was discovered by Dmitrti Ivanovsky in 1892, and its function was later elaborated by Martinus Willem Beijerinck in 1898, as well as coining the famous term, virus [10]. Clonal selection theory was developed in the late 1950s and early 1960s through three difference scientists independently, whose theories mirror our current understanding very similarly. Additionally, in 1957, British bacteriologist Alick Isaacs and Swiss microbiologist Jean-Jacques Lindenmann discovered the first cytokine, in which they coined as an "interferon". They observed that virally infected cells secrete this substance to protect neighboring cells through stimulating anti-viral cellular activity [11]. So far, communication via interferons or cytokines between the neuro and immune systems has become the central of neuroimmune axis [12].

\section{Method}

This review was conducted through the literature searches of the PubMed, Uni- 
versity of Kentucky Library and InfoKat Discovery databases. The keywords were use including hypothalamic, pituitary, thyroid, neuroendocrinology and immunoendocrinology. Articles published in English from 1952 for the field of background to 2020 for of the up-to-date were included.

\section{Hypothalamic-Pituitary-Thyroid Axis}

Thehypothalamic parvocellular neurons releases neuropeptide thyrotropinreleasing hormone (TRH) into the medial eminence, which circulates the hormone into the hypophysial-portal system [13]. There, TRH stimulates production of glycoprotein thyroid stimulating hormone (TSH) in the anterior pituitary, which is released into the main bloodstream (Figure 1). TSH is composed of two subunits, TSH $\alpha$ and TSH $\beta$, where the $\alpha$ subunit stabilizes the molecule while the $\beta$ subunit is utilized for TSH affinity and specificity [14]. TSH stimulates production of triiodothyronine (T3) and thyroxine (T4) from the thyrocytes in the follicles of the thyroid gland, which is then released into the bloodstream [15]. Their production and storage in the follicles are mainly facilitated by a protein called thyroglobulin. T3 and T4 serve to mobilize energy stores in peripheral tissues by stimulating mitochondrial function, sodium/potassium ATPase, and oxygen consumption. T3 is a more potent and active thyroid hormone than T4 but has less half-life. Additionally, T4 tends to be converted to T3 via deiodinase in peripheral tissues. The hypothalamus and anterior pituitary have negative feedback signals based on the amount of free $\mathrm{T} 3$ and $\mathrm{T} 4$ in the blood via nuclear T3R receptors, regulating transcription of the upstream TSH and TRH signals (Figure 1).

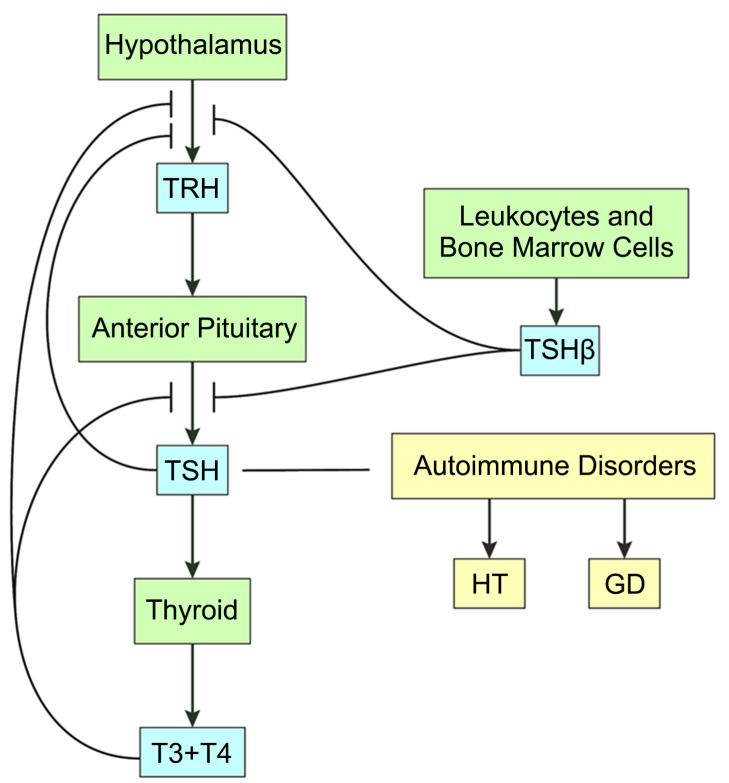

Figure 1. Overview of Hypothalamic-Pituitary-Thyroid axis associated with immunology and autoimmune disorders. TRH: Thyroid releasing hormone. TSH: Thyroid secreting hormone. TSH $\beta$ : Thyroid secreting hormone, beta. T3: Triiodothyronine. T4: Thyroxine. GD: Grave's Disease. HT: Hashimoto’s Thyroiditis. 
The HPT axis is thoroughly involved in controlling metabolic rate, thermogenesis, maintenance of muscle/nerve reflexes, and reproduction. In fasting states, T3 and T4 circulating levels decrease due to inhibited TRH expression. Thus, T3/T4 energy consumption is reduced, conserving energy. Leptin, a fed-state signal, abolishes this inhibition directly at the TRH neurons, or indirectly via the arcuate-paraventricular pathway [16]. Under cold exposure, brown adipose tissue is signaled by $\mathrm{T} 3$ via thyroid receptors which prompts the upregulation of mitochondrial activity to increase energy consumption to generate heat. Thus, hypothyroidism, or reduced T3 and T4 levels, have expected outcomes of cold intolerance, weight gain, bradycardia, and muscle weakness [13]. On the other hand, hyperthyroidism, or excessive thyroid hormone levels, will have symptoms of heat intolerance, weight loss, and tachycardia [17].

\section{Hypothalamic-Pituitary-Thyroid and Immune System}

Leukocytes such as dendritic cells have been shown to migrate from the bone marrow to the thyroid and produce local TSH [18]. Additionally, hematopoietic stem cells produce TSH and have TSH receptor expression; TSH in turn stimulates production of TNF- $\alpha$ in the bone marrow, which is important in the development of dendritic cell precursors [19]. Other cell populations such as the intestinal intraepithelial lymphocytes and epithelial cells also produce TSH and mature in reaction to the signal during a bacterial or viral infection [20]. The most notable observation is that the TSH produced from these bone marrow cells and leukocytes in the thyroid is a TSH $ß$ alternatively spliced variant [14]. The hypothesis behind the purpose of the TSH $\beta$ variant is to reduce T3/T4 production either by negative feedback on pituitary-made TSH or some other form of disruption [21]. Leukocyte-produced TSH $\beta$ has been seen to ramp up under infection, potentially to improve energy conservation and rest, which would match with the physical observations of lethargy and malaise in infected hosts. Schaefer and Klein also surmise that in normal conditions, the leukocyte-derived TSH $\beta$ is also under T3/T4 negative feedback like the pituitary-derived TSH [14]. Additionally, these native thyroid-residing dendritic cells have been shown to regulate the growth of thyrocytes via IL-1 $\beta$ and IL-6 [22].

The most notable human diseases involving the dysfunction of the HPT axis and the immune system are Graves' disease (GD) and Hashimoto's thyroiditis (HT). GD is an autoimmune disorder that involves auto-antibodies binding to the TSH receptors causing overproduction of TSH which increases T3 and T4, resulting in hyperthyroidism [14] [17]. These autoantibodies emerge from TSH receptor-reactive $B$ cells that survive deletion and self-tolerance mechanisms. HT is the mirror image of Graves' disease; thyrocytes undergo apoptosis via Fas death receptor signaling from thyroid-infiltrating lymphocytes [23] [24]. This autoimmunity also stems from disruption of self-tolerance mechanisms that prevent detection of self-proteins and creation of autoantigens. Thyroglobulin is most commonly targeted in autoimmune thyroid disease. Once detected by the MHC class II receptor on an antigen-presenting cell (APC) such as a dendritic 
cell, the APC processes and presents antigens of the thyroglobulin to naïve $\mathrm{T}$ cells. This gives rise to clonal expansion and maturation of $\mathrm{T}$ cells, which can also stimulate IgG anti-thyroglobulin antibody production in the B cells. The activation and clonal expansion of $\mathrm{B}$ and $\mathrm{T}$ cells mark the initial phase of destruction in HT; in the later phase, T-helper type 1 cells accumulate in the thyroid and cause destruction of thyrocytes via the Fas pathway, leading to hypothyroidism. In light of discovering TSH $\beta$-producing leukocytes, Schaefer and Klein assert that the hypothyroidism in HT could be brought on by the excessive recruitment of these leukocytes which would inhibit pituitary-made TSH, lowering T3/T4 production in the thyroid [14]. Conversely, in GD, the excessive pituitary-made TSH would increase T3/T4 production, inducing negative feed-back on TSH $\beta$ leukocyte production and disrupting its natural function of suppression.

\section{Therapeutic Applications}

Investigating the relationship and communication between metabolism and the immune system has expanded our view on the mechanism behind many metabolic diseases that are not limited to the discussed Graves' disease and Hashimoto's thyroiditis. For example, obesity tends to have a bidirectional effect in increasing risk of developing hypothyroidism, as it is associated with a low-grade systemic inflammation that could involve TSH $\beta$ pathways described by Schaefer and Klein [25]. GD is currently treated with either radioactive iodine, anti-thyroid drugs, or surgery to reduce the amount of thyrocytes in the thyroid via radioactive toxicity, immune-mediated apoptosis, or physical means, respectively [26]. However, that is not without pronounced side effects. Radioactive iodine treatment results in permanent hypothyroidism, such that the patient must receive lifelong synthetic hormone replacement to maintain TSH levels [27]. Anti-thyroid drugs often do not result in complete remission of Graves' disease and usually encompass a higher dose or a cocktail for patients that have larger goiter size and have a family history of GD. Yet, these three do not target the immunological mechanism behind GD, which is the antibody that stimulates TSH receptors. On the other hand, HD is treated with synthetic T4, which has mixed results. Around $10 \%$ of hypothyroid patients will still complain about persistent symptoms, even with normal TSH levels. Further studies are still needed to be done on combining synthetic T3/T4 in a ratio of 1:13 or 1:20, as a treatment that may potentially alleviate these symptoms [26].

However, the overlap of the relationship between the HPT axis and the immune system has not been well-investigated beyond thyroid autoimmunity. Further investigation of these fields can bring awareness to additional underlying mechanisms of metabolic diseases, potentially allowing us to also devise novel treatments that come from a new multidisciplinary perspective.

\section{Conflicts of Interest}

The author declares no conflicts of interest regarding the publication of this paper. 


\section{References}

[1] Filipp, G., Szentivanyi, A. and Mess, B. (1952) Anaphylaxis and the Nervous System. Acta Medica Academiae Scientiarum Hungaricae, 3, 163-173. https://doi.org/10.1007/BF02022520

[2] Isaacs, A. and Lindenmann, J. (1957) Virus Interference. I. The Interferon. Proceedings of the Royal Society of London. Series B-Biological Sciences, 147, 258-267. https://doi.org/10.1098/rspb.1957.0048

[3] Frederick Wheelock, E. (1965) Interferon-Like Virus-Inhibitor Induced in Human Leukocytes by Phytohemagglutinin. Science, 149, 310-311. https://doi.org/10.1126/science.149.3681.310

[4] Hull, G. (1998) Caleb Hillier Parry 1755-1822: A Notable Provincial Physician. SAGE Publications Ltd., London, 335-338. https://doi.org/10.1177/014107689809100618

[5] Loriaux, D.L. (2016) Caleb Hillier Parry (1755-1822). In: Lynn Loriaux, D., Ed., $A$ Biographical History of Endocrinology, John Wiley \& Sons, Ltd., Hoboken, 77-81. https://doi.org/10.1002/9781119205791.ch20

[6] Mitchell, P. (1961) Coupling of Phosphorylation to Electron and Hydrogen Transfer by a Chemi-Osmotic Type of Mechanism. Nature, 191, 144-148. https://doi.org/10.1038/191144a0

[7] Tata, J.R., Ernster, L. and Lindberg, O. (1962) Control of Basal Metabolic Rate by Thyroid Hormones and Cellular Function. Nature, 193, 1058-1060. https://doi.org/10.1038/1931058a0

[8] Joseph-Bravo, P., Jaimes-Hoy, L., Uribe, R.M. and Charli, J.L. (2015) TRH, the First Hypophysiotropic Releasing Hormone Isolated: Control of the Pituitary-Thyroid Axis. BioScientifica Ltd., Bristol, T85-T100. https://doi.org/10.1530/JOE-15-0124

[9] Lerner, K.L. and Lerner, B.W. (2003) World of Microbiology and Immunology. Gale, Detroit.

https://www.worldcat.org/title/world-of-microbiology-and-immunology/oclc/50080 $\underline{347}$

[10] Bos, L. (1999) Beijerinck's Work on Tobacco Mosaic Virus: Historical Context and Legacy. Philosophical Transactions. Biological Sciences, 354, 675-685. https://doi.org/10.1098/rstb.1999.0420

[11] Taylor, M.W. (2014) Interferons. In: Taylor, M.W., Ed., Viruses and Man: A History of Interactions, Springer, Berlin, 101-119. https://doi.org/10.1007/978-3-319-07758-1 7

[12] Quan, N. and Banks, W.A. (2007) Brain-Immune Communication Pathways. Brain, Behavior, and Immunity, 21, 727-735. https://doi.org/10.1016/j.bbi.2007.05.005

[13] Widmaier, E.P., Raff, H., Strang, K.T. and Vander, A.J. (2015) Vander's Human Physiology: The Mechanisms of Body Function. McGraw-Hill Higher Education, Boston.

[14] Schaefer, J.S. and Klein, J.R. (2011) Immunological Regulation of Metabolism-A Novel Quintessential Role for the Immune System in Health and Disease. The FASEB Journal, 25, 29-34. https://doi.org/10.1096/fj.10-168203

[15] Nillni, E.A. (2010) Regulation of the Hypothalamic Thyrotropin Releasing Hormone (TRH) Neuron by Neuronal and Peripheral Inputs. Frontiers in Neuroendocrinology, 31, 134-156. https://doi.org/10.1016/j.yfrne.2010.01.001

[16] Fekete, C. and Lechan, R.M. (2014) Central Regulation of Hypothalamic-PituitaryThyroid Axis under Physiological and Pathophysiological Conditions. Endocrine 
Reviews, 35, 159-194. https://doi.org/10.1210/er.2013-1087

[17] Mathew, P. and Rawla, P. (2020) Hyperthyroidism. StatPearls Publishing, Treasure Island. https://www.ncbi.nlm.nih.gov/books/NBK537053

[18] Klein, J.R. and Wang, H.C. (2004) Characterization of a Novel Set of Resident Intrathyroidal Bone Marrow-Derived Hematopoietic Cells: Potential for ImmuneEndocrine Interactions in Thyroid Homeostasis. Journal of Experimental Biology, 207, 55-65. https://doi.org/10.1242/jeb.00710

[19] Wang, H.-C., Dragoo, J., Zhou, Q. and Klein, J.R. (2003) An Intrinsic Thyrotropin-Mediated Pathway of TNF- $\alpha$ Production by Bone Marrow Cells. Blood, 101, 119-123. https://doi.org/10.1182/blood-2002-02-0544

[20] Scofield, V.L., Montufar-Solis, D., Cheng, E., Estes, M.K. and Klein, J.R. (2005) Intestinal TSH Production Is Localized in Crypt Enterocytes and in Villus "Hotblocks" and Is Coupled to IL-7 Production: Evidence for Involvement of TSH during Acute Enteric Virus Infection. Immunology Letters, 99, 36-44.

https://doi.org/10.1016/j.imlet.2004.12.010

[21] Persani, L., Cangiano, B. and Bonomi, M. (2019) The Diagnosis and Management of Central Hypothyroidism in 2018. Endocrine Connections, 8, R44-R54. https://doi.org/10.1530/EC-18-0515

[22] Simons, P.J., Delemarre, F.G.A. and Drexhage, H.A. (1998) Antigen-Presenting Dendritic Cells as Regulators of the Growth of Thyrocytes: A Role of Interleukin- $1 \beta$ and Interleukin-6. Endocrinology, 139, 3148-3156.

https://doi.org/10.1210/endo.139.7.6110

[23] Chistiakov, D.A. (2005) Immunogenetics of Hashimoto's Thyroiditis. BioMed Central, London, 1-21.

[24] Salmaso, C., Bagnasco, M., Pesce, G., Montagna, P., Brizzolara, R., Altrinetti, V., Richiusa, P., Galluzzo, A. and Giordano, C. (2002) Regulation of Apoptosis in Endocrine Autoimmunity. Annals of the New York Academy of Sciences, 966, 496-501. https://doi.org/10.1111/j.1749-6632.2002.tb04253.x

[25] Song, R.-H., Wang, B., Yao, Q.-M., Li, Q., Jia, X. and Zhang, J.-A. (2019) The Impact of Obesity on Thyroid Autoimmunity and Dysfunction: A Systematic Review and Meta-Analysis. Frontiers in Immunology, 10, 2349. https://doi.org/10.3389/fimmu.2019.02349

[26] Yoo, W.S. and Chung, H.K. (2016) Recent Advances in Autoimmune Thyroid Diseases. Endocrinology and Metabolism, 31, 379-385.

https://doi.org/10.3803/EnM.2016.31.3.379

[27] Ross, D.S., Burch, H.B., Cooper, D.S., Greenlee, M.C., Laurberg, P., Maia, A.L., Rivkees, S.A., Samuels, M., Sosa, J.A., Stan, M.N. and Walter, M.A. (2016) 2016 American Thyroid Association Guidelines for Diagnosis and Management of Hyperthyroidism and Other Causes of Thyrotoxicosis. Thyroid, 26, 1343-1421. https://doi.org/10.1089/thy.2016.0229 